\title{
A model for late Quaternary methane ice core signals: Wetlands versus a shallow marine source
}

\author{
Kieran D. O’Hara ${ }^{1}$ \\ Received 10 October 2007; revised 30 November 2007; accepted 13 December 2007; published 25 January 2008.
}

[1] A three-reservoir model with first order kinetics for methane records in the Vostok (Antarctica) and GISP2 (Greenland) ice cores reproduces the sawtooth pattern and the maximum and minimum concentrations. The model also returns an atmospheric methane relaxation time of $\sim 10$ years for both cores, which is the same as current estimates. The characteristics of the source reservoirs are long relaxation times (33.3 and $100 \mathrm{ky}$ ) and high initial methane concentrations (2500 and $7000 \mathrm{ppm}$ ) for GISP2 and Vostok, respectively. These characteristics are consistent with gas hydrate sources in shallow marine sediments, but not with wetland sources which have insufficient storage capacity and low source strength. Citation: O'Hara, K. D. (2008), A model for late Quaternary methane ice core signals: Wetlands versus a shallow marine source, Geophys. Res. Lett., 35, L02712, doi:10.1029/ 2007 GL032317.

\section{Introduction}

[2] The greenhouse gases, methane and carbon dioxide, show a remarkable coherence with each other and with $\delta^{18} \mathrm{O}$ in ice cores from Greenland [Brook et al., 1996] and Antarctica [Petit et al., 1999; EPICA Community Members, 2006] and also with the global $\delta^{18} \mathrm{O}$ deep-sea record [Lisiecki and Raymo, 2005], all of which show in-phase cyclic sawtooth patterns [Kennett et al., 2003]. The ice core records display Milankovitch-type orbital forcing periodicities at $100 \mathrm{ka}$ (eccentricity), $41 \mathrm{ka}$ (obliquity) and $23 \mathrm{ka}$ (precession) [Petit et al., 1999; Brook et al., 1996].

[3] The global methane budget maybe better understood than $\mathrm{CO}_{2}$ because of methane's shorter atmosphere relaxation time $(\sim 10$ years $)$ and it's fewer sources and sinks [Denman et al., 2007]. The main methane sink is due to oxidation in the atmosphere, namely $\mathrm{CH}_{4}+\mathrm{OH}=\mathrm{CH}_{3}+$ $\mathrm{H}_{2} \mathrm{O}$, which controls the methane atmosphere relaxation time [Khalil et al., 2000; Denman et al., 2007].

[4] The main source for methane during glacial/interglacial periods is thought to be wetlands in the tropics, due to anaerobic decay of organic matter, with more northern latitude wetlands and Arctic permafrost playing a smaller role [Raynaud et al., 1988; Chappellaz et al., 1993; Brook et al., 1996]. An alternative large source of methane is gas hydrates (clathrates) in shallow marine sediments [Kvenvolden and Lorenson, 2001; Buffett and Archer, 2004]. This reservoir may have been a major source of

\footnotetext{
${ }^{1}$ Department of Earth and Environmental Sciences, University of Kentucky, Lexington, Kentucky, USA.
}

Copyright 2008 by the American Geophysical Union. 0094-8276/08/2007GL032317\$05.00 atmospheric methane during earlier interglacial warm periods [Nisbet, 1990; Dillon et al., 2001; Kennett et al., 2003].

[5] Because the Milankovitch orbital forcing curves are smooth and do not display sawtooth patterns [Hays et al., 1976], the basic premise here is that the ice core signals reflect orbital forcing modulated by the source reservoir characteristics. Here I use a simple kinetic model tuned to the dominant frequency of the methane record in two ice cores, one from Antarctica (Vostok) and one from Greenland (GISP2). The model allows a distinction to be made between the gas hydrate and wetland source hypotheses.

\section{Methane Ice Core Records}

\subsection{Vostok}

[6] Figure 1a shows the $420 \mathrm{ka}$ methane record from the Vostok ice core [Petit et al., 1999]. The gross pattern is a sawtooth shape with a $\sim 100$ ka periodicity superimposed by $41 \mathrm{ka}$ and $23 \mathrm{ka}$ cycles. Peak concentrations ( $700 \mathrm{ppb})$ occur during short interglacials and progressively lower concentrations (down to $\sim 350 \mathrm{ppb}$ ) occur during longer glacial periods. Peaks and troughs coincide with orbitally forced northern latitude summer insolation variations. Glacial cycles (I-IV) have durations of $\sim 118 \mathrm{ky}$ (I), $110 \mathrm{ky}$ (II), $\sim 85 \mathrm{ky}$ (III) and $\sim 100 \mathrm{ky}$ (IV). Cycle III is shortest and shows lower amplitude compared to the others (Figure 1a). Interglacials lasted from a few ka to $28 \mathrm{ka}$.

\subsection{GISP2}

[7] Figure 1b shows the shorter, but higher resolution, $110 \mathrm{ka}$ year methane record from the Greenland Ice Sheet Project 2 core [Brook et al., 1996]. Peaks and troughs also coincide with northern latitude summer insolation variations caused by orbital precession with periods of 19-23 ka [Brook et al., 1996]. Major events include the Younger Dryas cooling (YD), interstadials 8 ( $\sim 38 \mathrm{ka}), 16 / 17$ ( $\sim 58 \mathrm{ka})$, $21(\sim 85 \mathrm{ka})$ and $23(\sim 100 \mathrm{ka})$. The best resolved interstadial warming event ( 8 at $38 \mathrm{ka}$ ) occurred within a very short period ( $\sim 100$ years) [Brook et al., 1996]. Glacial lows and interglacial highs correspond to 350 to $750 \mathrm{ppb}$, respectively, and are similar to the Vostok core concentrations. The sawtooth patterns require a rapid pulsed methane source that slowly recharges with time and then discharges rapidly to repeat the cycle.

\section{Description of Kinetic Model}

[8] The model involves three reservoirs, namely the source (reservoir A), the atmosphere (reservoir B), and the sink:

$$
\text { Source } A_{0} \stackrel{k_{1}}{\longrightarrow} \text { Atmosphere } B_{0} \stackrel{k_{2}}{\longrightarrow} \text { Sink }
$$




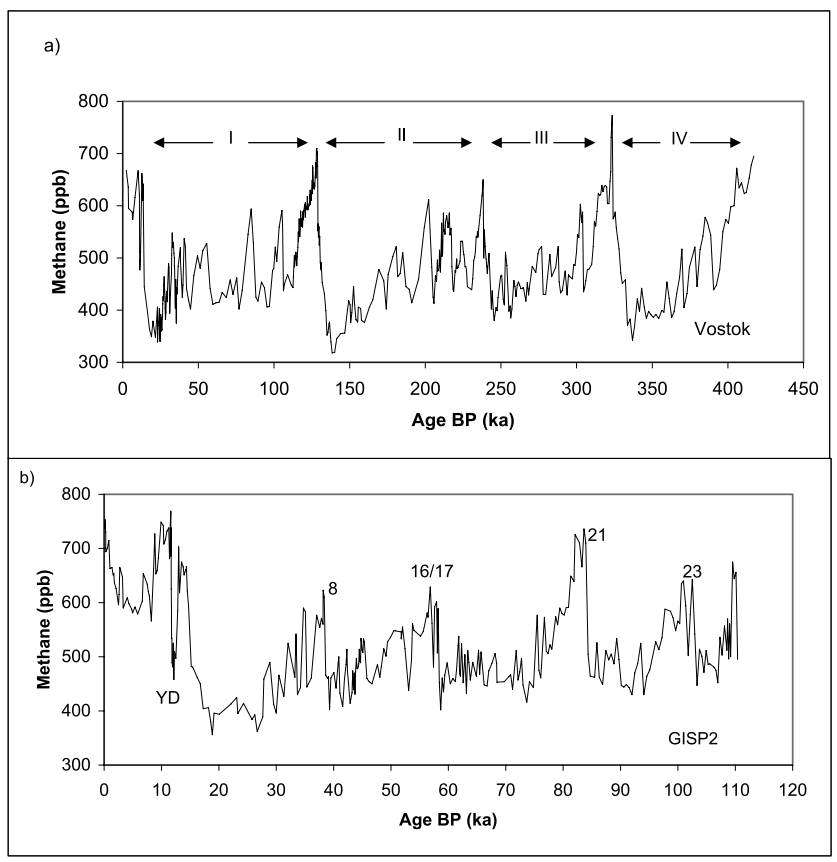

Figure 1. (a) Methane record for the Vostok (Antarctica) ice core [Petit et al., 1999]. The four main glacial cycles (IIV) have an interglacial periodicity of $\sim 100 \mathrm{ka}$. (b) Methane record for the GISP2 (Greenland) ice core [Brook et al., 1996]. Major events include the Younger Dryas cooling (YD, $12 \mathrm{ka})$ and interstadials 8 ( $\sim 38 \mathrm{ka}), 16 / 17$ ( $\sim 58 \mathrm{ka})$, $21(\sim 85 \mathrm{ka})$ and $23(\sim 100 \mathrm{ka})$. Interstadials have a periodicity of $\sim 23 \mathrm{ka}$.

Natural sources (wetlands or marine sediments) supply methane to the atmosphere, where $k_{1}$ is the source rate constant. Methane is destroyed (by oxidation) in the atmosphere (reservoir $B$ ) at a rate given by $k_{2}$, the sink rate constant. The initial methane amounts are $A_{o}$ and $B_{o}$ in reservoir $A$ and $B$, respectively. It is assumed that these reservoirs obey first order kinetics, so that reservoir $A$ releases methane to reservoir $B$ in proportion to the amount present, and reservoir $B$ loses methane in proportion to the amount present. Lasaga [1981] has outlined evidence in favor of first order kinetics in several global systems and experimental evidence confirms that the oxidation of methane by $\mathrm{OH}$ in the atmosphere follows a first order rate law [Vaghjiani and Ravishankara, 1991].

[9] The change in the amount of methane in reservoir $A$ is then given by

$$
-d A / d t=k_{1} A
$$

where $\mathrm{A}$ is the methane mass in reservoir $A$, and $t$ is time. The negative sign indicates the amount in the source decreases with time. Equation (1) can be integrated to give the amount of methane at any time

$$
A=A_{o} \exp \left(-k_{1} t\right)
$$

where $A_{o}$ is the initial amount in reservoir $A$ at time $t=0$. The amount of methane added to reservoir $B$ is then $k_{1} A$, and the amount being removed is $-\mathrm{k}_{2} \mathrm{~B}$, so that the net change in the atmosphere is

$$
d B / d t=k_{1} A-k_{2} B
$$

Substituting equation (2) into equation (3) gives

$$
d B / d t=k_{1} A_{o} \exp \left(-k_{1} t\right)-k_{2} B
$$

This expression can be integrated to give

$$
B=B_{o} \exp \left(-k_{2} t\right)+\left[k_{1} A_{o} /\left(k_{2}-k_{1}\right)\right]\left[\exp \left(-k_{1} t\right)-\exp \left(-k_{2} t\right)\right]
$$

Since the ice cores report methane concentrations (ppb), the amounts of methane in equation (5) can be converted to concentrations by dividing by the respective reservoir volumes, $\mathrm{V}_{\mathrm{A}}$ and $\mathrm{V}_{\mathrm{B}}$. Equation (5) is rewritten as:

$$
B^{\prime}=B_{o}^{\prime} \exp \left(-k_{2} t\right)+\left[k_{1} A_{o}^{\prime} /\left(k_{2}-k_{1}\right)\right]\left[\exp \left(-k_{1} t\right)-\exp \left(-k_{2} t\right)\right]
$$

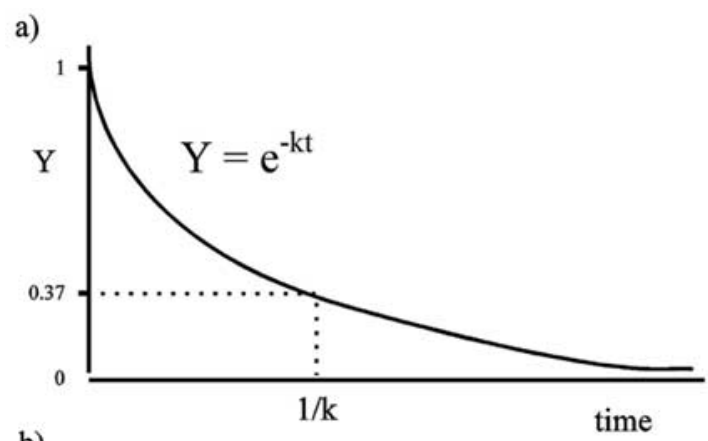

b)

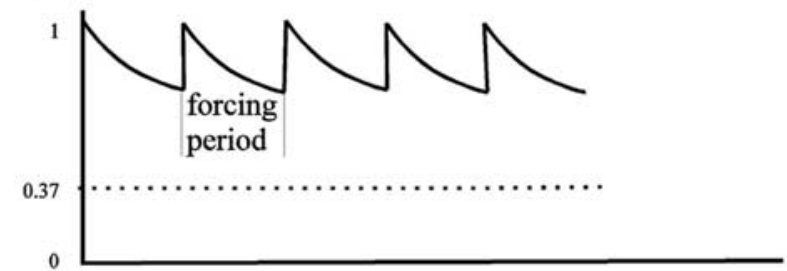

c)

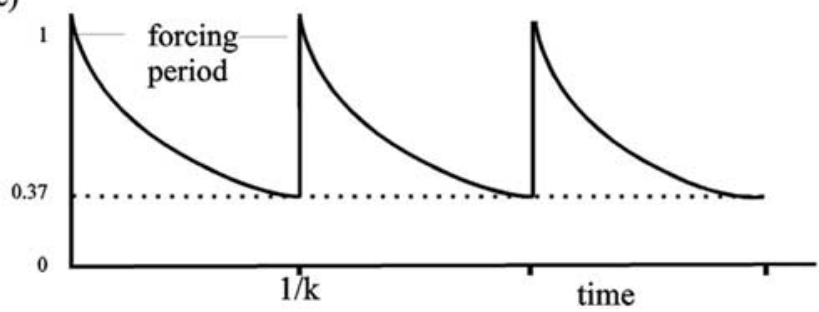

Figure 2. Relationship between relaxation time and forcing period. (a) Graph of the function $y=e^{-k t}$ where $t$ is time, $\mathrm{k}$ is the rate constant, and $1 / \mathrm{k}$ is the relaxation time, which equals $\mathrm{e}^{-1}(\sim 0.37)$. (b) The forcing period is substantially less than the relaxation time $(1 / \mathrm{k})$, resulting in a low amplitude (high frequency) signal. (c) The forcing period is approximately the same as the relaxation time, resulting in a higher amplitude (low frequency) signal. 

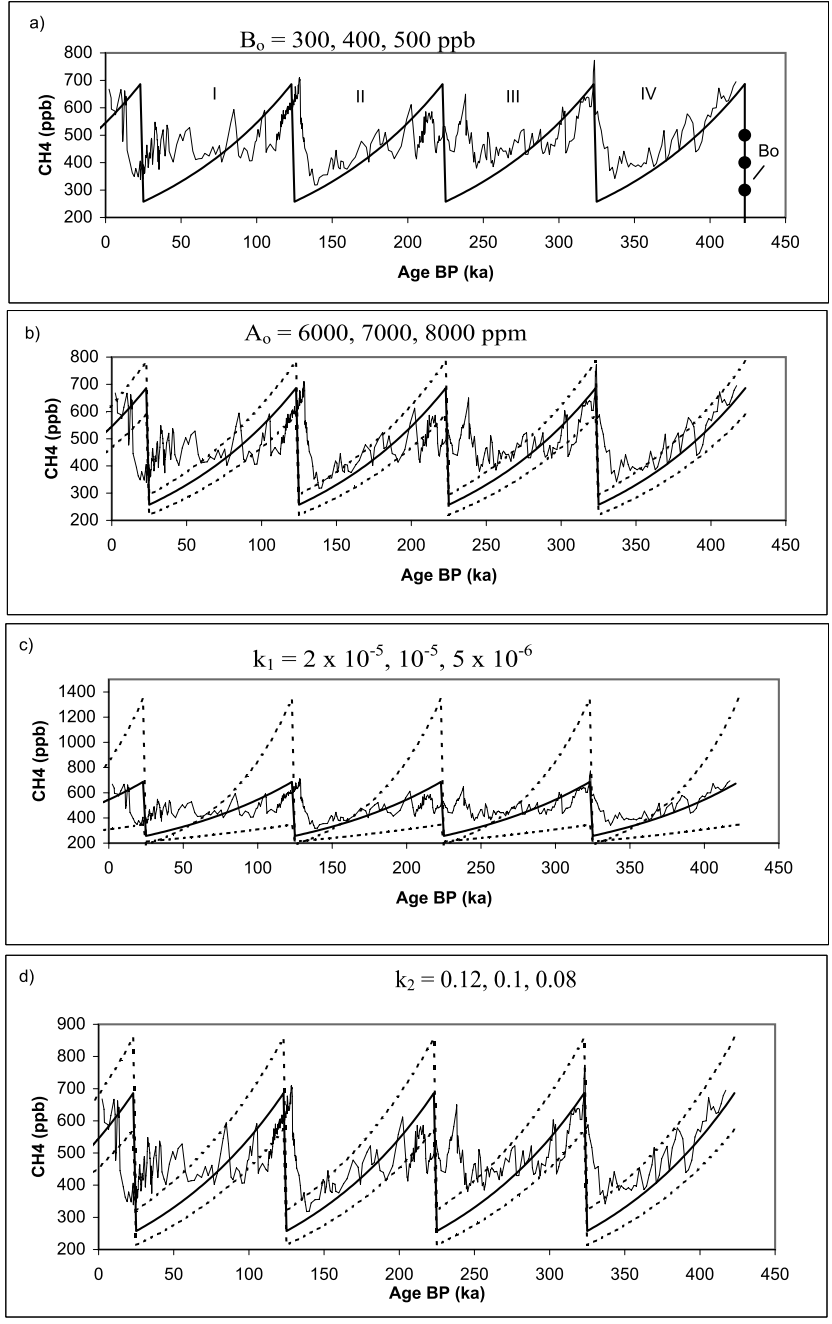

Figure 3. (a) Model results using three different initial atmospheric methane concentrations, $\mathrm{B}_{\mathrm{o}}$, of 300,400 and $500 \mathrm{ppb}$ (solid dots). The value of $B_{\mathrm{o}}$ has no effect on the long-term evolution of the system. Other values are $A_{o}=$ $7000 \mathrm{ppm}, \mathrm{k}_{1}=10^{-5} \mathrm{yr}^{-1}, \mathrm{k}_{2}=0.1 \mathrm{yr}^{-1}$. (b) Three model curves showing the effect of different values of the source reservoir initial concentration, $\mathrm{A}_{\mathrm{o}}^{\prime}$, of $6,000 \mathrm{ppm}$ (lower dashed curve), 8,000 ppm (upper dashed curve) and $7,000 \mathrm{ppm}$ (solid curve). $\mathrm{A}_{\mathrm{o}}^{\prime}=7,000 \mathrm{ppm}$ gives the best fit to the data. Other values are the same as before, with $\mathrm{B}_{\mathrm{o}}=0$. (c) Three model curves showing the effect of different values of the source reservoir rate constant, $\mathrm{k}_{1}$, of $2 \times 10^{-5} \mathrm{yr}^{-1}$ (upper dashed curve), $5 \times 10^{-6} \mathrm{yr}^{-1}$ (lower dashed curve) and $10^{-5} \mathrm{yr}^{-1}$ (solid curve). $\mathrm{k}_{1}=10^{-5}$ gives the best fit to the data, corresponding to a relaxation time of $10^{5}$ years. Other values the same as before. (d) Three model curves showing the effect of different values of the atmosphere sink rate constant, $\mathrm{k}_{2}$, of $0.08 \mathrm{yr}^{-1}$ (lower dashed curve), $0.12 \mathrm{yr}^{-1}$ (upper dashed curve) and 0.1 (solid curve). $\mathrm{k}_{2}=0.1 \mathrm{yr}^{-1}$ gives the best fit to the data, corresponding to a methane relaxation time of 10 years. Other values as before. where $B^{\prime}=B / V_{B}, B_{o}^{\prime}=B_{o} / V_{B}$ and $A_{o}^{\prime}=A_{o} / V_{A}$. Reservoir volumes are estimated later.

[10] In the model, reservoirs are activated in cycles determined by the observed periodicities in the Vostok $(\sim 100 \mathrm{ka})$ and Greenland core $(23 \mathrm{ka})$. Equation (6) is evaluated using a computer routine so that the concentration at the end of a forcing period is used as the initial concentration in the next period.

[11] To clarify features of the model, the relaxation (or residence time) of the function $y=e^{-k t}$ is shown graphically in Figure 2a. When $t=1 / k, y=e^{-1}$. This is the time taken for the function to decay to 0.368 times the initial concentration. The relaxation (or residence) time is defined as $\tau=$ $1 / k$, where $k$ is the rate constant. If the exponential function is subjected to forcing with a period substantially less than the relaxation time, a relatively high frequency, low amplitude, signal results (Figure 2b). However, if the forcing period is similar to (or longer than) the relaxation time a lower frequency, higher amplitude, signal results (Figure 2c). The amplitude of the signal is determined by the factor $k_{1} A_{o}^{\prime} /\left(k_{2}-k_{1}\right)$ in equation (6).

\section{Model Results for Vostok and GISP2 Cores}

[12] Three of the four variables $\left(\mathrm{k}_{1}, \mathrm{k}_{2}, \mathrm{~A}_{\mathrm{o}}, \mathrm{B}_{\mathrm{o}}\right)$ are kept constant and the fourth is varied until the best fit to the data is found by trial and error. Figure 3 shows model results for the Vostok core using equation (6). The data are modeled with 4 cycles with a $100 \mathrm{ka}$ periodicity over $420 \mathrm{ka}$. The effect of the initial concentration in the atmosphere, $\mathrm{B}^{\prime}{ }_{\mathrm{o}}$, is evaluated using concentrations of 300, 400 and $500 \mathrm{ppb}$ (parts per billion) (Figure 3a). Other values are $\mathrm{A}_{0}^{\prime}=$ $7000 \mathrm{ppm}$ (parts per million), $\mathrm{k}_{1}=10^{-5} \mathrm{yr}^{-1}, \mathrm{k}_{2}=$ $10^{-1} \mathrm{yr}^{-1}$. Except for the different $\mathrm{B}^{\prime}{ }_{\mathrm{o}}$ values at $\mathrm{t}=0$ (solid dots, Figure 3a), the three model curves are identical, indicating the initial concentration in reservoir $\mathrm{B}$ has no influence on the evolution of the system for $t>0$.

[13] Figure $3 \mathrm{~b}$ models the effect of varying the value of the source reservoir initial concentration, $\mathrm{A}_{\mathrm{o}}^{\prime}$, with values of $6000 \mathrm{ppm}$ (lower dashed line), $8000 \mathrm{ppm}$ (upper dashed line, and $7000 \mathrm{ppm}$ (solid curve). Other values are $\mathrm{B}_{\mathrm{o}}^{\prime}=0$,

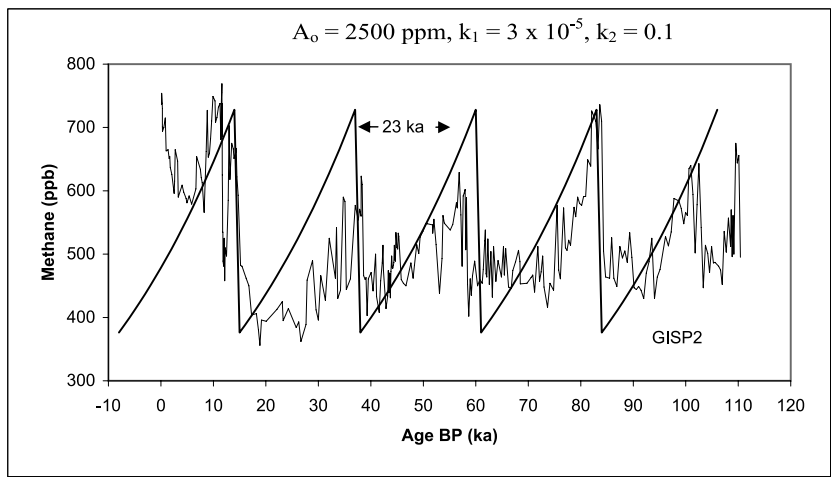

Figure 4. Plot of best-fit model results using equation (6) with a period of 23 ka years for the GISP2 ice core. Best fit values are initial concentration of source $\mathrm{A}_{\mathrm{o}}^{\prime}=2500 \mathrm{ppm}$, rate constant $\mathrm{k}_{1}=3 \times 10^{-5} \mathrm{yr}^{-1}$ and atmosphere rate constant $\mathrm{k}_{2}=0.1 \mathrm{yr}^{-1}$. Source $\left(\tau_{1}\right)$ and atmosphere $\left(\tau_{2}\right)$ relaxation times are $33.3 \mathrm{ky}$ and 10 years, respectively. 
$\mathrm{k}_{1}=10^{-5}$ and $\mathrm{k}_{2}=10^{-1}$ as before. The best fit to the data corresponds to $\mathrm{A}_{\mathrm{o}}^{\prime}=7000 \mathrm{ppm}$.

[14] Figure 3c models the effect of changing the value of the source rate constant $k_{1}$, with three different values: $2 \times$ $10^{-5} \mathrm{yr}^{-1}$ (upper dashed curve), $5 \times 10^{-6} \mathrm{yr}^{-1}$ (lower dashed curve) and $10^{-5} \mathrm{yr}^{-1}$ (solid curve). The value $\mathrm{k}_{1}=$ $10^{-5}$ provides the best fit to the data, corresponding to a relaxation time $\tau(=1 / \mathrm{k})$ of $10^{5}$ years.

[15] Figure $3 \mathrm{~d}$ models the effect of changing $\mathrm{k}_{2}$, the sink rate constant, with three different values: 0.12 (upper dashed curve), 0.08 lower dashed curve and 0.1 (solid curve). The data are bracketed by the range $0.08-0.12$ with $\mathrm{k}_{2}=0.1$ giving the best fit. These values corresponds to a relaxation time in the atmosphere $(\tau=1 / \mathrm{k})$ of 8.3 to 12.5 years with a best estimate of 10 years, similar to the current methane relaxation time of $8.7 \pm 1.3$ years [Denman et al., 2007].

[16] In a similar fashion, Figure 4 shows the best-fit model results for the GISP2 ice core (Figure 1b) with a period of $23 \mathrm{ky}$. The best fit values are: $\mathrm{A}_{\mathrm{o}}^{\prime}=2,500 \mathrm{ppm}$, $\mathrm{k}_{1}=3 \times 10^{-4}$ and $\mathrm{k}_{2}=0.1$. As before, the atmosphere initial value $\left(\mathrm{B}_{\mathrm{o}}^{\prime}\right)$ does not affect the evolution of the system. The best value of the source reservoir rate constant $\left(3 \times 10^{-4}\right)$ corresponds to a relaxation time $\tau_{1}\left(1 / \mathrm{k}_{1}\right)$ of $33.3 \mathrm{ky}$. The best value for the atmospheric relaxation time $\tau_{2}\left(1 / \mathrm{k}_{2}\right)$ is $\sim 10$ years, the same value inferred for the Vostok core.

[17] Bearing in mind that the $100 \mathrm{ky}$ and the $23 \mathrm{ky}$ cycles are not strictly periodic, and that they are superimposed by higher frequency cycles, the models reproduce the sawtooth shape of the data, and also the maximum and minimum concentrations reasonably well. To summarize, the source reservoir relaxation times $\left(\tau_{1}\right)$ are $33.3 \mathrm{ky}$ and $100 \mathrm{ky}$ for GISP2 and Vostok, respectively, and source reservoir initial concentrations are 2500 and 7000 ppm methane for GISP2 and Vostok, respectively. Both cores yield a methane atmosphere relaxation time $\left(\tau_{2}\right)$ of $\sim 10$ years, the same as current estimates.

\section{Source Reservoir Characteristics}

[18] Since mass equals concentration times volume, the global mass of methane in wetland reservoirs is equal to the methane concentration ( $\mathrm{ppm}$ or $\mathrm{mg} / \mathrm{kg}$ ) times the reservoir volume $\left(\mathrm{m}^{3}\right)$. Measurements of methane fluxes in wetlands vary substantially depending on season, latitude and precipitation, with higher fluxes in tropical wetlands compared to more northern latitudes [Matthews, 2000]. Bearing in mind that glacial climate was dryer compared to today's climate [Kennett et al., 2003], current wetland methane fluxes can be used as a maximum estimate during interglacial and interstadial conditions. Modern wetlands have a total area of $5.3 \times 10^{12} \mathrm{~m}^{2}$ [Matthews, 2000], and assuming a mean depth of $1 \mathrm{~m}$ gives a reservoir volume of $5.3 \times$ $10^{12} \mathrm{~m}^{3}$. The initial reservoir concentration of $7000 \mathrm{ppm}$ ( $\mathrm{A}_{\mathrm{o}}^{\prime}$ above) corresponds to $7 \mathrm{~g} / \mathrm{kg}$, and assuming the methane source has a density of $1000 \mathrm{~kg} / \mathrm{m}^{3}$ (or $1 \mathrm{~g} / \mathrm{cc}$ ), this corresponds to $7000 \mathrm{~g} / \mathrm{m}^{3}$. Multiplying this concentration by the volume of wetlands yields a total mass of $37.1 \times$ $10^{15} \mathrm{~g}$. The mean annual flux of today's wetlands is only $0.175 \pm 0.05 \times 10^{15} \mathrm{~g} \mathrm{yr}^{-1}$ [Denman et al., 2007, Table 7.6], too low by a factor of 200 .

[19] Although wetlands typically develop over thousands of years (e.g. peat bogs), methane emissions are seasonal and the wetland relaxation time will be very short (annual) due to lack of storage capacity. A wetland source would need to store 200 years worth of methane (or alternatively, have 200 times the current estimated volume) to account for the Vostok ice core signal; both these scenarios are implausible. The same conclusion applies to the GISP2 core $\left(\mathrm{A}^{\prime}{ }_{\mathrm{o}}=\right.$ $2500 \mathrm{ppm}$ ), where the wetland flux would be 70 times too small. The source characteristics of wetlands therefore do not meet the requirements of the ice core data, either in source strength or relaxation time. Kennett et al. [2003] also show that wetlands could not have responded fast enough to produce the observed rapid methane pulses.

[20] The area of ocean floor that is fertile for hydrate methane production is estimated to be $10^{7} \mathrm{~km}^{2}$ over a depth of $\sim 300 \mathrm{~m}$ [Buffett and Archer, 2004], giving a source volume of $3 \times 10^{15} \mathrm{~m}^{3}$. Multiplying this volume by the concentration of $7000 \mathrm{~g} / \mathrm{m}^{3}$ (Vostok) or $2500 \mathrm{~g} / \mathrm{m}^{3}$ (GISP2) yields 7.5 to $21 \times 10^{18} \mathrm{~g}$. These values are the same order as estimates of global methane clathrates [Kvenvolden and Lorenson, 2001; Buffett and Archer, 2004]. Blake Ridge (offshore South Carolina, USA), whose sediments date to $\sim 75 \mathrm{ka}$, has probably been continuously active over this period [Holbrook, 2001]. Sediment subduction rates offshore Peru indicate the gas fields there are about $87 \mathrm{ka}$ old [Percher et al., 2001]. These ages are consistent with relaxation times of $\sim 100 \mathrm{ky}$. These considerations indicate the shallow marine source is sufficient to meet the model requirements in both cores.

\section{Conclusions}

[21] The characteristic sawtooth pattern of the ice core data with periods of $100 \mathrm{ky}$ and $23 \mathrm{ky}$ and the approximate minima and maxima concentrations are reproduced by a three reservoir kinetic model. The currently accepted modern atmospheric relaxation time for methane ( $\sim 10$ years) is predicted by the model for both the Vostok and GISP2 cores. An important result is that the methane source reservoir must have high initial methane concentrations (2500 and $7000 \mathrm{ppm}$ ) and long relaxation times (33.3 and $100 \mathrm{ky})$. These considerations indicate that gas hydrates in shallow marine sediments meet the requirements of the bestfit models, whereas wetland sources do not.

[22] Acknowledgments. I thank William Dillon for a review of an earlier version of the manuscript and an anonymous reviewer.

\section{References}

Brook, E. J., T. Sowers, and J. Orchardo (1996), Rapid variations in atmosphere methane concentration during the past 110,000 years, Nature, 273, 1087-1091

Buffett, B., and D. Archer (2004), Global inventory of methane clathrate: Sensitivity to changes in the deep ocean, Earth Planet. Sci. Lett., 227, $185-199$.

Chappellaz, J., T. Blunier, D. Raynaud, J. M. Barnola, J. Schwander, and B. Stauffer (1993), Synchronous changes in atmospheric $\mathrm{CH}_{4}$ and Greenland climate between 40 and $8 \mathrm{ka}$, Nature, 366, 443-445.

Denman, K. L., et al. (2007), Couplings between changes in the climate system and biogeochemistry, in Climate Change 2007: The Physical Science Basis. Contribution of Working Group I to the Fourth Assessment Report of the Intergovernmental Panel on Climate Change, edited by S. Solomon et al., Cambridge Univ. Press, Cambridge, U. K.

Dillon, W. P., J. W. Nealon, M. H. Taylor, M. W. Lee, R. M. Drury, and C. H. Anton (2001), Seafloor collapse and methane venting associated with gas hydrate on the Blake Ridge: Causes and implications to seafloor stability and methane release, in Natural Gas Hydrates, Occurrence, Distribution, 
and Detection, Geophys. Monogr. Ser., vol. 124, edited by C. K. Paull and W. P. Dillon, pp. 211-233, AGU, Washington, D. C.

EPICA Community Members (2006), One-to-one coupling of glacial climate variability in Greenland and Antarctica, Nature, 444, 195-198, doi:10.1038/nature 05301

Hays, J. D., J. Imbrie, and N. J. Shackleton (1976), Variations in the Earth's orbit: Pacemaker of the Ice Ages, Science, 194, 1121-1132.

Holbrook, W. S. (2001), Seismic studies of the Blake Ridge: Implications for hydrate distribution, methane expulsion, and free gas dynamics, in Natural Gas Hydrates, Occurrence, Distribution, and Detection, Geophys. Monogr. Ser., vol. 124, edited by C. K. Paull and W. P. Dillon, pp. 235-256, AGU, Washington, D. C.

Kennett, J. P., K. G. Cannariato, I. L. Hendy, and R. J. Behl (2003), Methane Hydrates in Quaternary Climate Change: The Clathrate Gun Hypothesis, edited by J. P. Kennett et al., 216 pp., AGU, Washington, D. C.

Khalil, M. A. K., M. J. Shearer, and R. A. Rasmussen (2000s), Methane sinks, distribution and trends, in Atmospheric Methane, Its Role in the Environment, edited by M. A. K. Khalil, pp. 86-97, Springer, New York.

Kvenvolden, K. A., and T. D. Lorenson (2001), The global occurrence of natural gas hydrates, in Natural Gas Hydrates, Occurrence, Distribution and Detection, Geophys. Monogr. Ser., vol. 124, edited by C. K. Paull and W. P. Dillon, pp. 3-18, AGU, Washington, D. C.

Lasaga, A. C. (1981), Dynamic treatment of geochemical cycles: Global kinetics, in Kinetics of Geochemical Processes, Rev. Mineral., vol. 8 , edited by A. C. Lasaga and R. J. Kirkpatrick, pp. 69-110, Mineral Soc. Am., Chantilly, Va.
Lisiecki, L. E., and M. E. Raymo (2005), A Pliocene-Pleistocene stack of 57 globally distributed benthic $\delta^{18} \mathrm{O}$ records, Paleoceanography, 20, PA1003, doi:10.1029/2004PA001071.

Matthews, E. (2000), Wetlands, in Atmospheric Methane, Its Role in the Environment, edited by M. A. K. Khalil, pp. 202-233, Springer, New York.

Nisbet, E. G. (1990), The end of the ice age, Can. J. Earth Sci., 27, 148 157.

Percher, I. A., N. Kukowski, C. R. Ranero, and R. von Huene (2001), Gas hydrates along the Peru and Middle America trench system, in Natural Gas Hydrates, Geophys. Monogr. Ser., vol. 124, edited by C. K. Paull and W. P. Dillon, pp. 257-271, AGU, Washington, D. C.

Petit, J. R., et al. (1999), Climate and atmospheric history of the past 420,000 years from the Vostok ice core, Antarctica, Nature, 399, 429436.

Raynaud, D., J. Chappellaz, J. M. Barnola, Y. S. Korotkevich, and C. Lorius (1988), Climatic and $\mathrm{CH}_{4}$ cycle implications of glacial-interglacial $\mathrm{CH}_{4}$ change in the Vostok core, Nature, 333, 655-657.

Vaghiiani, G. L., and A. R. Ravishankara (1991), New measurement of the rate coefficient for the reaction of $\mathrm{OH}$ with methane, Nature, 350, 406408

K. D. O'Hara, Department of Earth and Environmental Sciences, University of Kentucky, Lexington, KY 40506-0053, USA. (geokoh@uky. edu) 